\title{
An Overview of Virtual Communities of Faculty Practice
}

Narjis Hyder, EdD

Walden University, Minneapolis, Minnesota, United States

Amy Adcock, EdD

Walden University, Minneapolis, Minnesota, United States

David Brown, EdD

Walden University, Minneapolis, Minnesota, United States

(iD) https://orcid.org/0000-0003-1326-8439

Contact: narjis.hyder@mail.waldenu.edu

\section{Abstract}

Virtual communities of faculty practice (CoP) provide support for and supplement the demanding doctoral curriculum with the purpose of assisting doctoral students through a holistic support system. This virtual community provides a positive private environment where faculty engage, share, and discuss current research questions or issues to encourage scholarship and collegiality. This scholarly essay presents an overview of faculty virtual CoPs in the context of mentoring online doctoral students. Attention is given to the definition of communities of practice, Wenger's communities of practice model, producing and sustaining communities of practice, and incorporation of virtual CoPs at the doctoral level.

Keywords: Virtual communities of practice; doctoral faculty; education

Date Submitted: April 24, 2020 | Date Published: December 31, 2020

\section{Recommended Citation}

Hyder, N., Adcock, A., \& Brown, D. (2020). An overview of virtual communities of faculty practice. Journal of Educational Research and Practice, 10, 420-426. https://doi.org/10.5590/JERAP.2020.10.1.27

\section{What are Communities of Practice?}

Communities of practice (CoPs) are distinguished from a network of friends or colleagues by their purpose and the inclusion of three specific elements shared by members: a common domain (e.g., mathematics), a set of practices and/or skills (e.g., problem solving instructional strategies), and a professional community (Wenger, 1998). CoPs are designed to gather experiences, stories, and best practices in a focused discipline. CoPs do more than just share stories, they create an environment where shared experiences, both successes and failures, of fellow community members inform future practice of the entire community. Common topics include student mentorship and professional development in completely online environments. Lave and Wenger (1991) proposed that this type of learning-situated in context and shaped by real-world communal interactions-provides an authentic environment, including subtleties that might be lost in simple transition of knowledge from one individual to another. 
CoPs are defined as a "learning partnership among people who find it useful to learn from and with each other about a particular domain. They use each other's experience of practice as a learning resource (Wenger et al., 2011, p. 9). CoPs usually consist of faculty and staff who share a common interest and meet regularly. The topic of the CoPs is something all members enjoy or are invested in. Therefore, CoP members learn how to improve practice in an area specific to the CoP's area of focus. The meetings lead to regular interaction, and conversations are knowledge and expertise based (Wenger et al., 2002). This article will provide an overview of faculty virtual CoPs in the context of mentoring doctoral students online.

\section{Producing Communities of Practice}

CoPs require three elements: domain, the community, and the practice. The domain gives the community an identity and includes key elements of what the group will address. The community is where members relate to each other around topics of shared interest for the purpose of helping each other. Practice is the third essential element of the CoP framework, in which there is not only a shared interest but also a requirement that members be practitioners in the field. Members can share their resources and experiences and discuss solutions to problems (Wenger, 1998). For example, in relation to the topic of this article, online doctoral faculty virtually collaborate and interact for the specific purpose of discussing their role as a dissertation mentor. The domain here would be the online doctoral faculty who work with dissertating students. The community is built around the shared topics related to their role as mentors to these students. The practice would be the activity related to the online mentoring of dissertating students.

\section{Theoretical Foundation of Communities of Practice}

The learning that occurs in CoPs is based on assumptions about the social learning that happens when members of the community participate in discussions focused on the defined domain or practice (Lave \& Wenger, 1991). Humans are social beings who acquire knowledge by negotiating practices and sharing experiences with others immersed in the same domain. Humans then implement theories, approaches, or practice based on these communal negotiations, linking those actions to practical or desired outcomes and presenting results and reflections back to the larger community (Farnsworth et al., 2016; Wenger, 1998).

The social learning at the foundation of CoPs resembles that of a cognitive apprenticeship because it occurs through expert to novice modeling and the sharing of successes and failures relevant to the community. The distinction between CoPs and apprenticeships relates to the level of experience of the participants. An apprenticeship is a focused, formal relationship between an expert who models and coaches and their apprentice who observes and practices (Brown et al., 1989). In CoPs, participants have a more informal relationship and can be at any level of expertise in the domain. The primary guidelines for participating include remaining focused on the domain and sharing information specific to practice. As with apprenticeships, CoP members share experiences with fellow practitioners in order to model or demonstrate successes and failures. Further learning occurs when the community reflects on advice or information presented in the CoP to determine whether to integrate a finding into best practices or whether practices should be amended or refined. At times, learning in CoPs is not a formal practice but is a product of formal reports or reflections of the community on the experiences stemming from new methods or practice that have been shared in the community.

\section{Doctoral CoPs Literature}

For this scholarly essay, we conducted a multiple-database literature search using the terms "virtual community of practice" and "doctoral faculty." A total of 11 articles focused on virtual CoPs in mentoring doctoral students online. Each of these articles was published in the last 3 years. This number was reduced to four when further limiters of being peer reviewed and appearing in a scholarly journal were applied. A 
common theme in these articles related to the importance of collaboration among doctoral faculty in online universities and programs. (Bedford, 2019; Berry, 2019; Owen et al., 2018; Scarpena et al., 2018; Soto et al., 2019).

In a 2019 study, Sharla Berry found that six types of professional collaboration contribute to building an online academic community. These include the use of asynchronous materials, facilitation and attendance at webinars, the use of guided practice sessions in the virtual classroom with an instructional designer, 24-houra-day technical phone line support sessions, the facilitation of in-class technical support, and holding a weekly virtual faculty meeting. Berry found each of these activities improved faculty engagement.

Faculty can engage in professional development and preparation using both synchronous and asynchronous methods. In a 2018 study, Scarpena and colleagues developed a three-pronged framework to improve professional development and professional practice among graduate online teaching faculty. This model emphasizes that teaching communities and organizations should all work together for an optimum experience. In a 2018 study by Owen and colleagues, researchers used an elements-of-value pyramid to find the value of experienced online faculty (i.e., mentors) working with newer online faculty (i.e., mentees). The results indicated that the values and outcomes in the online CoP mirrored those experiences in the traditional, face-to-face environment.

Soto et al. (2019) explored a virtual CoP consisting of five mathematics higher education instructors that previously participated in a face-to-face CoP. Participants indicated that they valued participation in regular online discussions about how to improve their teaching. The use of social media as a platform for virtual CoPs was examined in a 2019 study by Bedford. In this study, 22 doctoral faculty completed a 10-item interview that assessed their use of social media after a 10-week virtual CoP experience. The results indicated that the use of social media was effective in promoting collaboration and a sense of community among doctoral faculty.

The use of virtual CoPs in higher education is a valuable resource that should be considered when having instructors work remotely. Virtual CoPs can be invaluable tools to help faculty hone teaching strategies and enhance professional development. As technology evolves and the demand for online instruction increases, leaders in institutions of higher education should investigate the feasibility of launching virtual CoPs for their faculty and staff.

\section{Social Theory of Learning Framework}

Wenger's social theory of learning consists of four learning components, as shown in Figure 1. These are community, practice, meaning, and identity (Wenger, 2009).

Community refers to learning as belonging, practice refers to learning by doing, meaning refers to learning by experiencing, and practice refers to learning by doing (Wenger, 1998). The social theory of learning entails sociality, relatedness, connectedness, and learning together, which can all occur in a CoP. For example, examining a virtual CoP comprised of online doctoral faculty requires discussion (i.e., sociality), generating relatedness among online doctoral faculty, having something in common to discuss (i.e., connectedness), and deriving solutions to problems as a group (i.e., learning together). Wenger (2009) stated social participation is necessary for learning to take place within a specific context. However, there is a gap in research examining the use and benefits of virtual CoPs among online doctoral faculty. 
Hyder et al., 2020

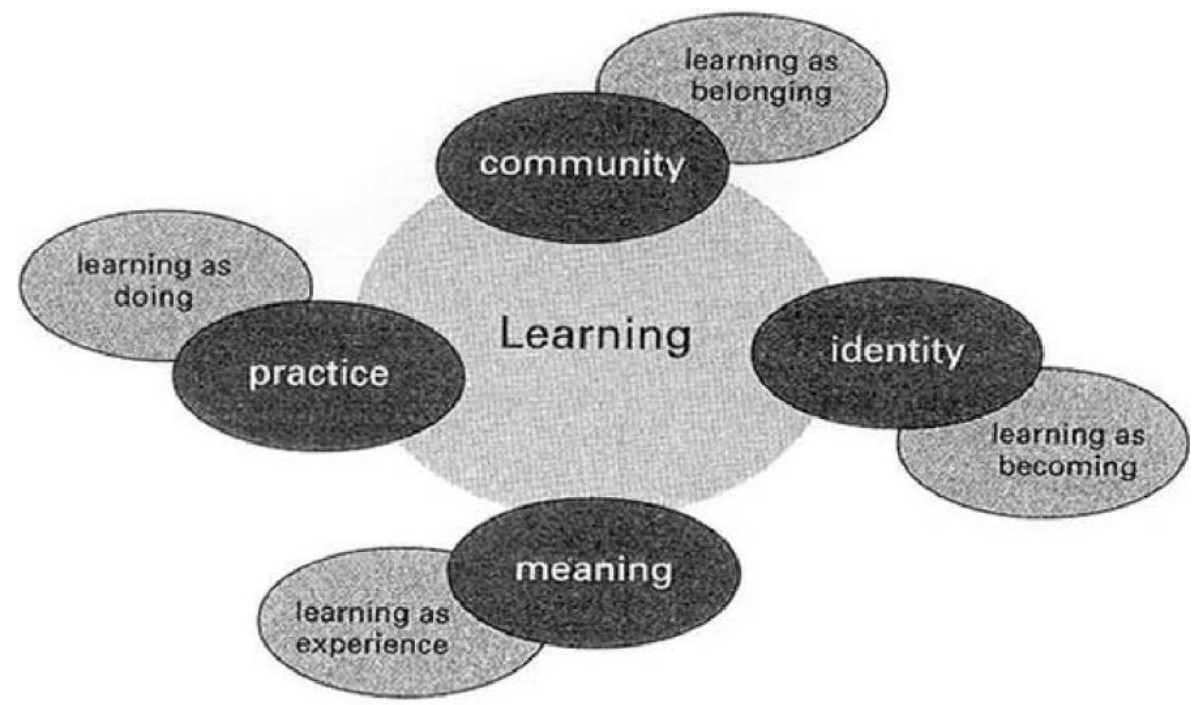

Figure 1: Social Theory of Learning Framework

Adapted from Wenger (1998).

\section{Sustaining Communities of Practice}

Maintaining CoPs consists of focused topic and skills discussions, clear expectations and timely communication, the fostering of personal communication, monthly synchronous meetings, the acceptance of shared responsibilities, and collaboration. Building engagement within a CoP can impact its sustainability. Positive engagement, where all voices are heard and respected, can create a sense of belonging within the community. Effective communication will help sustain a CoP from year to year (Masika \& Jones, 2016). Additionally, to be sustainable, a CoP must meet the needs of its members. These needs can include providing opportunities to meet virtually or face-to-face, being flexible about how and when meetings take place, and otherwise being responsive to member needs. The members of the CoP ideally should be knowledgeable on resources within their shared area of expertise in order to add value as a contributing member of the community. Having a leader assigned to a $\mathrm{CoP}$ who can organize topics for the month based on group consensus, set up the time and virtual location for meetings, and relay clear expectations will also sustain and retain CoPs.

In a study conducted by Patton and Parker (2017), collaboration and engagement within a CoP reduced isolation, therefore extending teaching and research capacities. This qualitative study explored physical education teachers' understanding of how participating in a CoP supported their own professional development. Social dynamics, common focus, professional relationships, safe but challenging spaces, and shared commitment were the results of this study. Probst and Borzillo (2008) discussed the 10 commandments of CoP governance that lead to the successful development and shared best practices as per the perspectives of $57 \mathrm{CoP}$ managers across U.S. and European companies. First, objectives should indicate a clear mission. Second, topics should be classified into subtopics to provide clarity and direction. Third, regular assessment of these overall objectives should be conducted. Fourth, the CoP should develop and share best practices. Fifth, members should remain current in the field by sharing what is being done by the experts. Sixth, participants should connect with other CoP members therefore increasing participation and best practices. Seventh, the leader needs to be effective at structuring and coordinating subtopics. Eighth, the leader should remind members that the CoP is a hierarchy free zone, so members understand mistakes are allowed and they will not be judged. Ninth, the objectives of the CoP should be measured and evidence that 
they are being met should be provided to the CoP leader (i.e., the university). Finally, CoP members should explain the process for implementing a best practice and provide explanations for how they used it (Probst \& Borzillo, 2008). These "10 commandments" provide an understanding of shared best practices and how to sustain faculty communities of practice in the context of mentoring doctoral students.

\section{Conclusion}

This scholarly essay provided an overview of faculty virtual CoPs in the context of mentoring doctoral students online. CoPs are distinguished from other social networks by focusing on a specific population of professionals sharing experiences to inform future practice. In the field of online doctoral education, interactions in virtual CoPs specifically directed at faculty mentoring practices are an emerging area of study. More research should be conducted to determine the best means of creating and sustaining effective faculty virtual CoPs for online dissertation mentors. 


\section{References}

Bedford, L. (2019). Using social media as a platform for a virtual professional learning community. Online Learning, 23(3), 120-136. https://doi.org/10.24059/olj.v23i3.1538

Berry, S. (2019). Professional development for online faculty: Instructors' perspectives on cultivating technical, pedagogical and content knowledge in a distance program. Journal of Computing in Higher Education, 31, 121-136. https://doi.org/10.1007/s12528-018-9194-0.

Brown, J. S., Collins, A., \& Duguid, P. (1989). Situated cognition and the culture of learning. Educational Researcher, 18(1), 32-42.

Farnsworth, V., Kleanthous, I., \& Wenger-Trayner, E. (2016). Communities of practice as a social theory of learning: A conversation with Etienne Wenger. British Journal of Educational Studies, 64(2), 139160. https://doi.org/10.1080/00071005.2015.1133799

Lave, J., \& Wenger, E. (1991). Situated learning: Legitimate peripheral participation. Cambridge University Press.

Masika, R. \& Jones, J. (2016). Building student belonging and engagement: Insights into higher education students' experiences of participating and learning together. Teaching in Higher Education, 21, 138150. https://doi.org/10.1080/13562517.2015.1122585

Owen, H., Whalley, R., Dunmill, M., \& Eccles, H. (2018). Social impact in personalized virtual professional development pathways. Journal of Educators Online, 15(1), 1-13.

Patton, K., \& Parker, M. (2017). Teacher education communities of practice: More than a culture of collaboration. Teaching and Teacher Education, 67, 351-360. https://doi.org/10.1016/j.tate.2017.06.013

Probst, G., \& Borzillo, S. (2008). Why communities of practice fail and why they succeed. European Management Journal, 26, 335-347. https://doi.org/10.1016/j.emj.2008.05.003

Scarpena, K., Riley, M., \& Keathley, M. (2018). Creating successful professional development activities for online faculty: A reorganized framework. Online Journal of Distance Learning Administration, 21(1), $1-9$.

Soto, M., Gupta, D., Dick, L., \& Appelgate, M. (2019). Bridging distances: Professional development for higher education faculty through technology-facilitated lesson study. Journal of University Teaching \& Learning Practice, 16(3), 1-19. https://ro.uow.edu.au/jutlp/vol16/iss3/7

Wenger, E. (1998). Communities of practice: Learning as a social system. Systems Thinker. https://thesystemsthinker.com/communities-of-practice-learning-as-a-social-system/

Wenger, E. (2009). A social theory of learning. In K. Illeris (Ed.), Contemporary theories of learning: Learning theorists ... In their own words (pp. 209-218). https://doi.org/10.4324/9781315147277

Wenger, E., McDermott, R. A., \& Snyder, W. (2002). Cultivating communities of practice: A guide to managing knowledge. Harvard Business Press.

Wenger, E., Trayner, B., \& de Laat, M. (2011). Promoting and assessing value creation in communities and networks: A conceptual framework. Ruud de Moor Centrum, Open University of the Netherlands. 
Hyder et al., 2020

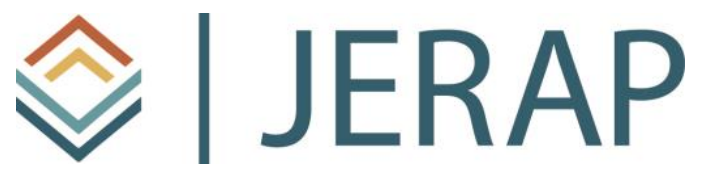

The Journal of Educational Research and Practice is a peerreviewed journal that provides a forum for studies and dialogue about developments and change in the field of education and learning. The journal includes research and related content that examine current relevant educational issues and processes. The aim is to provide readers with knowledge and with strategies to use that knowledge in educational or learning environments. JERAP focuses on education at all levels and in any setting, and includes peer-reviewed research reports, commentaries, book reviews, interviews of prominent individuals, and reports about educational practice. The journal is sponsored by the Richard W. Riley College of Education and Leadership at Walden University, and publication in JERAP is always free to authors and readers. 